Journal of Mammalogy, 81(3):726-733, 2000

\title{
MOTHER-YOUNG INTERACTIONS IN A MATERNITY COLONY OF MYOTIS FORMOSUS
}

\author{
Huei-Ping Shen ANd Ling-Ling LeE* \\ Department of Zoology, National Taiwan University, Taipei, Taiwan, \\ Republic of China \\ Present address of HPS: Taiwan Endemic Species Research Institute, Nantou, Taiwan, \\ Republic of China
}

The maternity colony of Myotis formosus in Yun-lin County, southwestern Taiwan, began to form in late March, and the numbers peaked (about 200) in May. Most bats left the roost site between mid-August and early October for unknown hibernation sites. Females gave birth during May and June. Before parturition, females $(n=19)$ spent 563.9 min \pm 47.28 SD outside the roost per night. Time away from the roost decreased significantly after they gave birth. Lactating females increased the total time that they spent outside the roost per night by $37.8 \%$ from early to late lactation. Females spent more time grooming young than self-grooming during the first 2 weeks of lactation. From the 3rd week on, more time was spent on self-grooming. Forearm length and body mass of newborns were $21.46 \pm 1.90 \mathrm{~mm}(n=13)$ and $3.71 \pm 0.41 \mathrm{~g}(n=12)$, about $42.8 \%$ and $24.1 \%$ of adult size, respectively. Young rarely moved during the 1 st week after birth. They started to crawl at the 2nd week and to attempt short straight-line flight at the 3 rd week. Females always rested next to their young while roosting in the first 2 weeks of lactation but separated from them from the 3 rd week on. Behavioral changes in females coincided with the growth and development of their young.

Key words: mother-young interactions, Myotis formosus, Taiwan

Many studies on activity patterns of bats have indicated that timing of emergence and return to the roosts are associated closely with sunrise and sunset (Catto et al. 1995; Erkert 1982; Stebbings 1968; Swift 1980). However, a few studies on breeding females indicated that their activity patterns change at different stages of reproduction (Barclay 1989; Brigham 1991; Clark et al. 1993; Rydell 1993). It is assumed that because energy demand of nursing females is high and females invest a lot in their offspring (Kurta and Kunz 1987; Speakman and Racey 1987; Wilde et al. 1995), foraging duration, number of foraging bouts, and even foraging distance of females may vary with the progression of different re-

\footnotetext{
*Correspondent:leell@ccms.ntu.edu.tw
}

productive conditions during the nursing period (Barclay 1989; Brigham 1991; Clark et al. 1993; Rydell 1993).

Myotis formosus is widely distributed in Asia. It is found from South Korea, Japan, Taiwan, southern China, Philippines, and Malaysia to northern India and eastern Afghanistan (Corbet 1978). The only known large colony in Taiwan is a maternity colony in Yun-lin County, southwestern Taiwan. Bats arrive at this roost site in late March, and their numbers peak in May. The majority of the colony members are females, although a small percentage of males also roost there in summer. Females give birth in May and June. Most bats leave between mid-August and early October. Their winter hibernaculum is unknown. Accord- 
ing to fecal analysis, the diet includes Coleoptera, Diptera, and Lepidoptera (Yang 1996).

Like many other bat species, $M$. formosus gives birth to 1 young/year. To ensure reproductive success, changes in female behavior during the nursing period should correlate with the growth and development of their young. Our purpose was to evaluate behavioral and activity changes of lactating females, growth and development of young, and mother-young interactions of $M$. for mosus during the nursing season.

\section{Materials ANd Methods}

The maternity colony of $M$. formosus roosted about $5 \mathrm{~m}$ on a beam under the eaves of a traditional house in a small village in Yun-lin County $\left(23^{\circ} 24^{\prime} \mathrm{N}, 120^{\circ} 14^{\prime} \mathrm{E}\right)$, southwestern Taiwan. Rice and sugarcane fields surrounded the village. The house was built in 1934. Since 1935, M. formosus has been present annually between late March and late August. Bats rested there during the day heedless of people talking or walking underneath. The owner of the house reported that thousands of bats used to line up on the beam decades ago, but the population has declined in recent years. Since 1993, <300 individuals have roosted at this site in summer.

Adult bats were captured weekly using butterfly nets from May to early June 1995. Capture was conducted $\leq 1 \mathrm{~h}$ before dusk emergence to reduce stress (Barclay and Bell 1988). Sex, length of forearm, and body mass were recorded. Each bat was released immediately after being banded with a colored plastic split ring (A. C. Hughes, Ltd., Middlesex, United Kingdom) for individual identification. Young were collected and marked from late May. To avoid disturbance and possible abandonment (Barclay and Bell 1988; Kunz 1974), marking of young took place while adults were out foraging and capture of adults ceased. Forearm length and body mass of young were measured at succesive captures to track growth.

Numbers of total and marked individuals roosting on the beam were recorded daily using 8 by 32 binoculars. Behavior of females and young during the day was videotaped between 0700 and $1000 \mathrm{~h}, 1100$ and $1400 \mathrm{~h}$, and 1500 and $1800 \mathrm{~h}$ weekly from late May to early $\mathrm{Au}-$ gust 1996. No extra light sources were needed when conducting observations and videotaping during the day. Self-grooming and grooming of young by marked adult females were observed. During night observations, bats entering or leaving the roost were detected with a QMC mini bat detector (QMC Instruments, Ltd., London, United Kingdom) and then checked briefly with a headlamp. Marked individuals staying on the beam were identified. Thus, number of foraging bouts and duration between each return of marked individuals were recorded. From midJune to early August 1996, separation and reunion of mother-young pairs were recorded from morning return until dusk emergence. Times of sunset and sunrise during summer were 1825-1850 $\mathrm{h}$ and 0510-0530 h, respectively.

\section{RESULTS}

A total of 169 individuals (82 adult females, 5 adult males, 82 juveniles) was marked in 1995. Of these marked bats, 89 $(52.7 \%)$ were recaptured later in the same year, and $58(34.3 \%)$ were recaptured in 1996 (Table 1).

Females.-Of the 82 females marked in $1995,46(56.1 \%)$ were recaptured at least once in 1995 . Thirty $(65.2 \%)$ of those 46 females returned to the roost site within 1 week. In 1996, 48 marked females reappeared, 23 of which were not recaptured in 1995. Among the 48 females, 21 disappeared after June before giving birth; 1 gave birth in mid-May, and 15 gave birth in June. Most females at this maternal roost gave birth in June. Marked females that gave birth stayed at the roost for an average of 105.7 days $\pm 19.11 S D(n=15)$ and generally left after mid-August. Three bats that gave birth earlier (in May or early June) left earlier in mid-June, mid-July, and early August.

Before parturition, females stayed outside the roost all night. They emerged at about $1900 \mathrm{~h}$ and returned between 0430 and $0500 \mathrm{~h}$. The mean total time away from their day roost was $563.9 \pm 47.28 \mathrm{~min}(n$ $=19$ ). After parturition, females returned to their day roost 1-3 times each night, and the total time away from their day roost decreased $(F=46.89$, d.f. $=1,29, P<$ 
TABLE 1.-Mark-recapture data for Myotis formosus in Yun-lin County, Taiwan, 1995 and 1996.

\begin{tabular}{|c|c|c|c|c|c|}
\hline & \multicolumn{2}{|c|}{ Adult } & \multicolumn{2}{|c|}{ Juvenile } & \multirow[b]{2}{*}{ Total } \\
\hline & Female & Male & Female & Male & \\
\hline \multicolumn{6}{|l|}{1995} \\
\hline Number of individuals marked & 82 & 5 & 38 & 44 & 169 \\
\hline $\begin{array}{l}\text { Number of marked individuals } \\
\text { returned }\end{array}$ & 46 & 1 & 19 & 23 & 89 \\
\hline Recapture rate $(\%)$ & 56.1 & 20.0 & 50.0 & 52.3 & 52.7 \\
\hline \multicolumn{6}{|l|}{1996} \\
\hline $\begin{array}{l}\text { Number of marked individuals } \\
\text { returned }\end{array}$ & 48 & 3 & 5 & 2 & 58 \\
\hline Recapture rate $(\%)$ & 58.5 & 60.0 & 13.2 & 4.6 & 34.3 \\
\hline
\end{tabular}

0.001). As young grew older, the duration of females' 1st and often the longest foraging bout increased, numbers of nightly returns dropped from 3 to 1 gradually, and total time females spent outside the roost
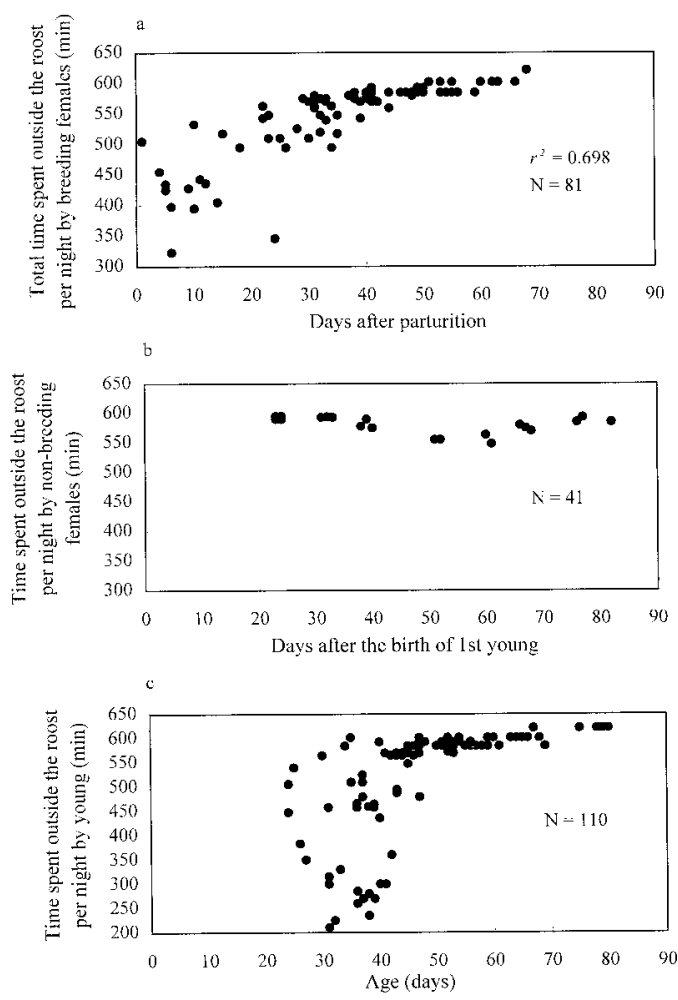

FIG. 1.- Time spent outside the roost per night by $M$. formosus a) breeding females during lactation, b) nonbreeding females, and c) young. increased (Fig. 1a). Duration of the 1st foraging bout was $148.0 \pm 49.36 \mathrm{~min}(n=$ 14), $266.4 \pm 100.20 \mathrm{~min}(n=14), 410.8$ $\pm 78.50 \mathrm{~min}(n=11)$, and $447.7 \pm 100.73$ $\min (n=19)$ when young were 1 week, 2 weeks, 3 weeks, and 1 month old, respectively. Total time females spent away from the roost was $401.8 \pm 46.24 \min (n=12)$, $453.0 \pm 58.39 \min (n=13), 541.0 \pm 22.35$ $\min (n=11), 553.8 \pm 23.61 \min (n=19)$, and $596.3 \pm 9.81 \mathrm{~min}(n=10)$ when young were 1 week, 2 weeks, 3 weeks, 1 month, and 2 months old, respectively. At the 3 rd week of lactation, time spent away from the roost increased $34.6 \%$ and was significantly longer than time spent away during the first 2 weeks of lactation $(F=12.47$, d.f. $=1$, 34, $P<0.05)$.

Females spent $0.8 \%$ of the daytime on self-grooming before parturition. There was no significant difference in the total time spent on self-grooming among the 0700$1000 \mathrm{~h}, 1100-1400 \mathrm{~h}$, and 1500-1800 h periods $(F=0.06$, d.f. $=2,15, P>0.05)$. Percentage of time spent on self-grooming decreased during the first 2 weeks of lactation $(0.5 \%)$ but did not differ significantly from that observed before parturition. By the 3rd week of lactation, time spent on self-grooming increased to $3.8 \%(F=$ 17.48 , d.f. $=1,15, P<0.001)$ and then dropped to $3.0 \%$ and $0.8 \%$ at the 4 th and 5 th weeks of lactation, respectively.

Five marked females that were consid- 
ered nonbreeding because neither young nor nursing behaviors were observed roosted with breeding females. Foraging duration for these nonbreeding females averaged $581.6 \mathrm{~min}$ and changed little during the whole breeding season (Fig. 1b). This pattern was different from that of breeding females. Nonbreeding females spent 2.2\% of the daytime on self-grooming, more time than did females during the first 2 weeks of lactation $(F=4.73$, d.f. $=1,26, P<0.05)$. Nonbreeding females stayed at this summer roost for an average of $112.5 \pm 7.42$ days $(n=5)$, which did not differ from the amount of time spent by breeding females $(t=-0.68$, d.f. $=18, P>0.05)$.

Five 1-year-old females born and marked in 1995 returned in 1996 (Table 1). Only 1 gave birth in mid-June. Starting on 24 June, the young of this female was no longer observed, and no more nursing behavior was seen. Thus, her young probably died. Nonbreeding 1-year-old females spent $15.3 \%$ and $2.1 \%$ of the daytime on self-grooming between late May and late June and in July-August, respectively $(F=40.80$, d.f. $=1,18, P<0.001)$.

Young.-Forty-four male and 38 female young were marked in 1995 , and $40.8 \%$ of them were never seen again. In summer 1996, 5 female and 2 male yearlings marked in 1995 returned. Young were nearly naked at birth. Their wings were wet and often folded. The umbilical cord became dry and fell off $\leq 3$ days after birth. The eyes opened and pinnae became erect within 1 week after birth. Their activity was limited, and they seldom changed roosting positions in this 1 st week. During this period, young would emit continuous weak sounds when they fell from the beam, during the marking process, and when females returned from foraging. After 1 week, the body was densely covered by grayish hair. At 11-12 days of age, young began to show behaviors such as push-ups, flapping, or fluttering (as defined by Hughes et al. 1995). Push-ups were most often seen during midday. The average frequency was
6.43 times/30 $\min (n=12)$, and the duration was 3-5 s each time. Young could crawl around swiftly when they were 2 weeks old. They could do some short straight-line flight at 15-21 days of age. After that, they would do a circling flight around the house, under the eaves, and in the front yard at night. One or 2 young might fly occasionally during the day. During this period, their hair color appeared darker than that of adults, otherwise it was difficult to distinguish between adults and young. Young could fly skillfully and forage at night after they were 1 month old, but they generally returned from their foraging flights $1-4 \mathrm{~h}$ earlier than adults. Total time spent outside the roost varied greatly with individuals (Fig. 1c). After they were 45 days old, individual differences diminished, and young spent nearly the same amount of time outside as adults $(F=2.01$, d.f. $=1,22, P>0.05)$.

Length of forearm and body mass of newborns were $21.46 \pm 1.90 \mathrm{~mm}(n=13)$ and $3.71 \pm 0.41 \mathrm{~g}(n=12)$, or $42.8 \%$ and $24.1 \%$ of adult size, respectively. There was no difference between sexes, and no correlation was found between body size and birth date. Growth of forearm was $1.39 \mathrm{~mm} /$ day when young were 1-7 days of age and 0.47 $\mathrm{mm}$ /day during the 3rd week. Increase in body mass was $0.24 \mathrm{~g} /$ day during the $1 \mathrm{st}$ week, $0.47 \mathrm{~g} /$ day during the $2 \mathrm{nd}$ week, and $0.14 \mathrm{~g} /$ day during the $3 \mathrm{rd}$ week. Growth rate decreased 60-70\% after the 3rd week, when young started to fly (Fig. 2).

Mother-young interactions.-Sixteen mother-young pairs were marked. Those mothers were seen taking care of the same young repeatedly. When mothers returned from their foraging bout, they actively searched for their offspring among masses of young. They would crawl around and touch nearby young with their muzzles. After showing interest in 1 individual among the crowd, they nudged the young toward themselves with wings and immediately stayed calm. It generally took mothers $<3$ min to find their own young. While mothers 

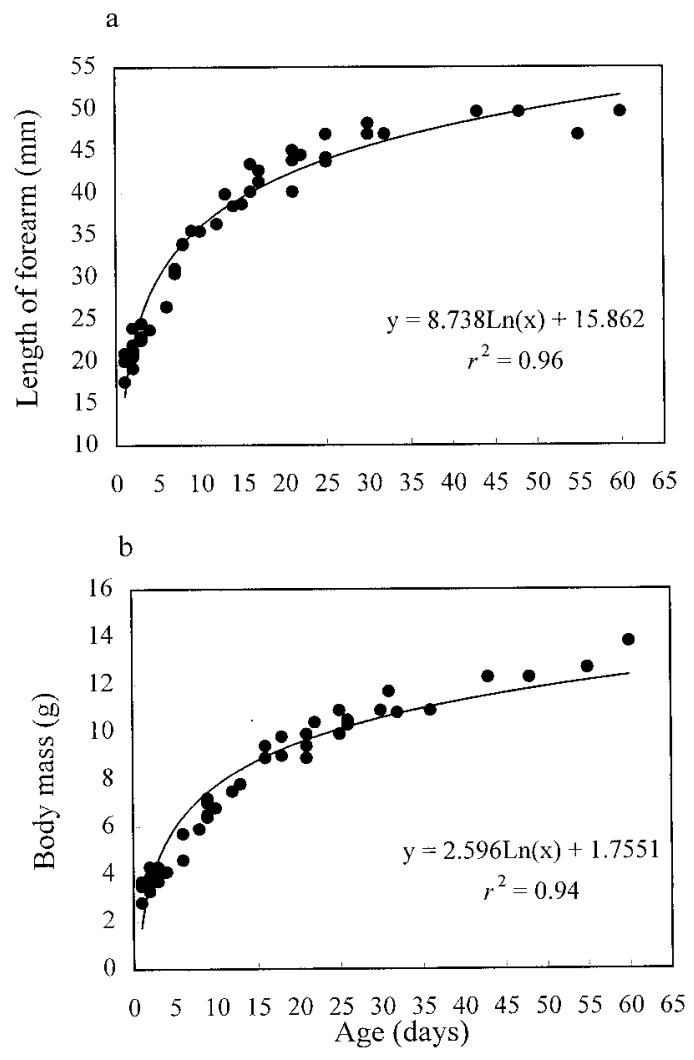

FIG. 2.-Growth of $M$. formosus young as measured by a) length of forearm and b) body mass.

were searching, many young attempted to sneak under them when they passed by.

Six male and 4 female young were observed to fall to the ground. The oldest was a 3-week-old female practicing flying, and the others were $<5$ days old. After measuring the length of forearm and weight, each young was hung back on the wall near the spot where it fell. The 3-week-old female flew back to the roosting beam, 2 young were preyed on by domestic cats, the rest were picked up by adult females. Adult females would nuzzle young at first and then stretched their wings to cover the young's entire body. At the same time, young would crawl onto the females. Usually, each young had only 1 adult female attempt to pick it up and return it to the roost. At dawn on 14 June 1995, 2 adult females tried to pick up 1 fallen young, but the young seemed hesitant to crawl onto either of them. After several minutes, another adult female flew down from the beam and attempted to pick up the young. In $<1 \mathrm{~min}$, the last female succeeded and returned to the roosting beam with the young. This was the only incidence in which $>1$ female bat tried to pick up a single young during the entire study; all of these bats were unmarked.

Young $<2$ weeks old usually were hidden under female bats and could not be seen easily. Female-young pairs always had body contact while roosting except when females went out foraging. At the 3 rd week of lactation when young were between 15 and 21 days of age, female-young pairs began to separate from each other while roosting, and duration of separation averaged $5.5 \%$ of the day. By the 4 th and 5 th week of lactation, duration of separation increased to $68.1 \%$ and $93.4 \%$ of the day, respectively ( 3 rd versus 4 th week, $F=61.85$, d.f. $=1,10, P<0.001 ; 4$ th versus 5 th week, $F=12.19$, d.f. $=1,15, P<0.05)$. Females usually initiated separation and reunion with their young, but when young were $>1$ month of age, they would actively seek their mothers for reunion (Fig. 3). On 5 occasions, young $>40$ days old attempted to sneak under their mothers. Mothers were indifferent to these approaches $(n=3)$, turned away from the young $(n=1)$, or assumed threatening postures toward the young, with the mouth slightly opened and a charge accompanied by a single call audible to human ears $(n=1)$. Mean distance between mothers and young when they were separated was $19.8 \pm 20.72 \mathrm{~cm}(n=$ 29). That distance changed little as lactation progressed.

Time spent on grooming of young by females decreased gradually during lactation. It averaged $5.7 \%$ of the daytime during the 1 st week of lactation, $3.8 \%$ during the 2 nd week, $2.6 \%$ during the 3 rd week, and $1.1 \%$ during the 4 th week. That behavior was never observed after the 4th week. Females 


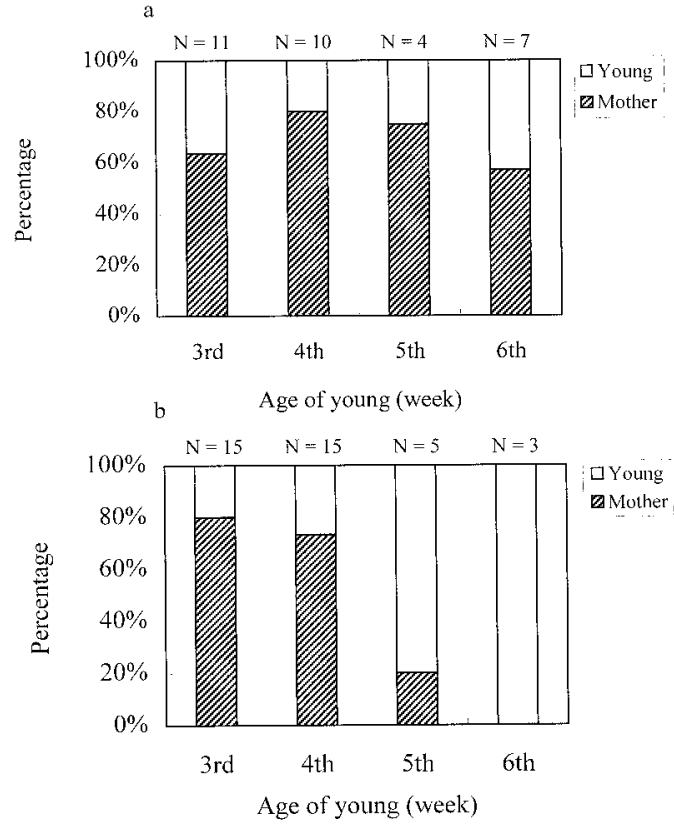

FIG. 3.-Percentage of $M$. formosus mother versus young initiating a) separation and b) reunion for young of various ages.

spent more time grooming young than selfgrooming during the first 2 weeks of lactation (1st week, $F=31.20$, d.f. $=1,8, P<$ $0.001 ; 2$ nd week, $F=20.80$, d.f. $=1,8, P$ $<0.05)$. On 1 occasion, a 16-day-old young licked its mother's face for $32 \mathrm{~s}$ after being groomed, which was the only observation in which a young groomed its mother.

When using length of forearm as the measure of body size, no relationship was found between body size of females and their parturition date $(r=-0.14, n=14$, $P>0.5$ ), body sizes of females and their newborn young $(r=0.52, n=14, P>$ 0.05 ), or body size of females having male or female young $(t=1.00, d . f .=14, P>$ $0.05)$.

\section{DISCUSSION}

Changes in time spent away from the roost per night and time spent on selfgrooming were observed in female $M$. formosus before and after lactation. Within 2 weeks after parturition, female $M$. formosus spent more time on grooming young during the day and less time foraging during the night. By the 3rd week of lactation, time spent outside the roost by females increased, and more time was spent on selfgrooming than on grooming young. Meanwhile, growth rates of young decreased 60$70 \%$ compared with that of the first 2 weeks. Young started to perform some short straight-line flight, and female-young pairs began to separate from each other while roosting. Behavioral changes in females coincide with growth and development of their young; similar changes were not seen in nonbreeding females.

Behavioral changes due to birth or development of young also have been recorded in other species of bats. In Pipistrellus subflavus (Winchell and Kunz 1996), females rested less and were more alert during the postpartum period; female grooming during the day also increased after young were born. The degree of increased time spent outside the roost per night by female bats varies among different species and different regions (Barclay 1989; Rydell 1993). The change in energy demand due to birth of newborn young and progression of lactation (Kunz 1987; Kurta and Kunz 1987; Speakman and Racey 1987; Wilde et al. 1995), the need for returning to nurse and keep young warm (Barclay 1989; Kunz 1987), and the change in food availability (Racey and Swift 1985) and foraging distance may all play a role in influencing the duration of foraging by female bats.

Young M. formosus increased duration of foraging bouts progressively as they aged. When they were about 45 days old, time spent by young outside the roost did not differ from that of adult females. Their diet also became similar to that of adults as they aged. Relative importance of various kinds of insects in the diet (determined by fecal examinations) showed no difference between young and adults when young were 45 days old (Yang 1996). Similar patterns and timing of development also have been recorded in young of other Myotis species. 
In M. velifer (Kunz 1974), juveniles started to forage when they were about 1 month old; they developed emergence and foraging behaviors similar to those of adults in the following 2 weeks. Their foraging efficiency also increased during this period. In M. myotis, radiotagged juveniles increased their foraging time and distance as they became older and foraged independently from their mothers (Audet 1990). In M. lucifugus, foraging patterns of juveniles and adults differed significantly (Adams 1997); shifts in habitat use and diet occurred as juveniles grew (Adams 1996). Such patterns and timing of development are crucial for young of species that need different sites for reproduction and hibernation, such as $M$. formosus, to become fully developed and survive autumnal migration.

Recognition between mother and young can be achieved through calls and odors (Balcombe 1990; Balcombe and McCracken 1992; De Fanis and Jones 1995a, 1995b; Gelfand and McCracken 1986; Gustin and McCracken 1987; Loughry and McCracken 1991; Matsumura 1979, 1981; McCracken and Gustin 1991). Female $M$. formosus would crawl around and touch nearby young with their muzzles when returning from foraging and would choose only 1 young to nurse. Young, on the contrary, would attempt to orient to any female nearby. In Rhinolophus ferrumequinum nippon, young $<2$ weeks of age emitted audible attracting calls to catch the mother's attention (Matsumura 1979), and motheryoung reunion was achieved by signal synchronization (Matsumura 1981). In our study, M. formosus young $<1$ week of age also emitted continuous weak sounds when females returned from foraging flight. Interactions between mother and young changed with the growth of young. Mothers became indifferent to their young during late lactation, whereas young became more active in seeking females for reunion. Responses of mothers to young also changed in Pipistrellus pipistrellus (Hughes et al. 1989); mothers did not encourage their young to suckle as often and became more indifferent to approaches by young as lactation proceeded. In Plecotus auritus, caregiving behavior of the mother declined as the young grew (McLean and Speakman 1997).

Ransome (1990) suggested that reproductive success would be better for older or larger female bats because they would give birth earlier or have larger young, resulting in young that are more fully developed before migration and hibernation. However, we found no relationship of body size between females and their young. However, among $5 \mathrm{M}$. formosus female yearlings, only 1 gave birth and its young survived for only 1 week, indicating that reproductive success of yearling M. formosus is low. Because determination of the ages of adult M. formosus is difficult, we were unable to compare reproductive success among females of different age groups, but this information is important for future investigations of mother-young interactions in this species.

\section{ACKNOWLEDGMENTS}

We thank C. H. Hsu and M. H. Hsu for permitting us to conduct this study at their house and S. H. Yang and C. H. Hu for helping with the field work.

\section{Literature Cited}

AdAMs, R. A. 1996. Size-specific resource use in juvenile little brown bats, Myotis lucifugus (Chiroptera: Vespertilionidae): is there an ontogenetic shift? Canadian Journal of Zoology 74:1204-1210.

ADAms, R. A. 1997. Onset of volancy and foraging patterns of juvenile little brown bats, Myotis lucifugus. Journal of Mammalogy 78:239-246.

AUDET, D. 1990. Foraging behavior and habitat use by a gleaning bat, Myotis myotis (Chiroptera: Vespertilionidae). Journal of Mammalogy 71:420-427.

BAlcomBE, J. P. 1990. Vocal recognition of young by mother Mexican free-tailed bats, Tadarida brasiliensis mexicana. Animal Behaviour 39:960-966.

Balcombe, J. P., And G. F. McCracken. 1992. Vocal recognition in Mexican free-tailed bats: do young recognize mothers? Animal Behaviour 43:79-87.

BARCLAY, R. M. R. 1989. The effect of reproductive condition on the foraging behavior of female hoary bats, Lasiurus cinereus. Behavioral Ecology and Sociobiology 24:31-37.

BARClAy, R. M. R., AND G. P. BELl. 1988. Marking and observational techniques. Pp. 59-75 in Ecolog- 
ical and behavioral methods for the study of bats (T. H. Kunz, ed.). Smithsonian Institution Press, Washington, D.C.

BRIGHAM, R. M. 1991. Flexibility in foraging and roosting behaviour by the big brown bat (Eptesicus fuscus). Canadian Journal of Zoology 69:117-121.

Catto, C. M. C., P. A. Racey, and P. J. Stephenson. 1995. Activity patterns of the serotine bat (Eptesicus serotinus) at a roost in southern England. Journal of Zoology (London) 235:635-644.

Clark, B. S., D. M. Leslie, JR., and T. S. Carter. 1993. Foraging activity of adult female Ozark bigeared bats (Plecotus townsendii ingens) in summer. Journal of Mammalogy 74:422-427.

Corbet, G. B. 1978. The mammals of the Palaearctic region: a taxonomic review. British Museum (Natural History), London, United Kingdom.

De FAnis, E., AND G. Jones. 1995a. Post-natal growth, mother-infant interactions and development of vocalizations in the vespertilionid bat Plecotus auritus. Journal of Zoology (London) 235:85-97.

De FAnis, E., AND G. Jones. 1995b. The role of odour in the discrimination of conspecifics by pipistrelle bats. Animal Behaviour 49:835-839.

ERKERT, H. G. 1982. Ecological aspects of bat activity rhythms. Pp. 201-242 in Ecology of bats (T. H. Kunz, ed.). Plenum Publishing, New York.

Gelfand, D. L., and G. F. McCracken. 1986. Individual variation in the isolation calls of Mexican free-tailed bat young (Tadarida brasiliensis mexicana). Animal Behaviour 34:1078-1086.

Gustin, M. K., and G. F. McCracken. 1987. Scent recognition between females and young in the bat Tadarida brasiliensis mexicana. Animal Behaviour 35:13-19.

Hughes, P. M., J. M. V. RAyner, AND G. Jones. 1995. Ontogeny of 'true' flight and other aspects of growth in the bat Pipistrellus pipistrellus. Journal of Zoology (London) 235:291-318.

Hughes, P. M., J. R. Speakman, G. Jones, and P. A. RACEY. 1989. Suckling behaviour in the pipistrelle bat (Pipistrellus pipistrellus). Journal of Zoology (London) 219:665-670.

KunZ, T. H. 1974. Feeding ecology of a temperate insectivorous bat (Myotis velifer). Ecology 55:693711.

KunZ, T. H. 1987. Post-natal growth and energetics of suckling bats. Pp. 395-420 in Recent advances in the study of bats (M. B. Fenton, P. A. Racey, and J. M. V. Rayner, eds.). Cambridge University Press, Cambridge, United Kingdom.

KuRTA, A., AND T. H. KunZ. 1987. Size of bats at birth and maternal investment during pregnancy. Symposia of the Zoological Society of London 57:79106.

Loughry, W. J., and G. F. MCCracken. 1991. Factors influencing female-young scent recognition in Mex- ican free-tailed bats. Journal of Mammalogy 72: 624-626.

Matsumura, S. 1979. Mother-infant communication in a horseshoe bat (Rhinolophus ferrumequinum nippon): development of vocalization. Journal of Mammalogy 60:76-84.

Matsumura, S. 1981. Mother-infant communication in a horseshoe bat (Rhinolophus ferrumequinum nippon): vocal communication in three-week-old infants. Journal of Mammalogy 62:20-28.

McCracken, G. F., AND M. K. Gustin. 1991. Nursing behavior in Mexican free-tailed bat maternity colonies. Ethology 89:305-321.

McLean, J. A., and J. R. Speakman. 1997. Non-nutritional maternal support in the brown long-eared bat. Animal Behaviour 54:1193-1204.

RACEy, P. A., AND S. M. SWIFT. 1985. Feeding ecology of Pipistrellus pipistrellus (Chiroptera: Vespertilionidae) during pregnancy and lactation. I. Foraging behaviour. The Journal of Animal Ecology 54:205215.

Ransome, R. D. 1990. Reproduction and development. Pp. 131-171 in The natural history of hibernating bats. Christopher Helm Press, London, United Kingdom.

RYDELL, J. 1993. Variation in foraging activity of an aerial insectivorous bat during reproduction. Journal of Mammalogy 74:503-509.

Speakman, J. R., And P. A. Racey. 1987. The energetics of pregnancy and lactation in the brown longeared bat, Plecotus auritus. Pp. 367-393 in Recent advances in the study of bats (M. B. Fenton, P. A. Racey and J. M. V. Rayner, eds.). Cambridge University Press, Cambridge, United Kingdom.

Stebbings, R. E. 1968. Measurements, composition and behaviour of a large colony of the bat Pipistrellus pipistrellus. Journal of Zoology (London) 156:15-33.

SwIFT, S. M. 1980. Activity patterns of pipistrelle bats (Pipistrellus pipistrellus) in northeast Scotland. Journal of Zoology (London) 190:285-295.

Wilde, C. J., M. A. KerR, AND P. A. Racey. 1995. Lactation in vespertilionid bats. Pp. 139-149 in Ecology, evolution and behaviour of bats (P. A. Racey and S. M. Swift, eds.). Oxford University Press, New York.

Winchell, J. M., AND T. H. Kunz. 1996. Day-roosting activity budgets of the eastern pipistrelle bat, Pipistrellus subflavus (Chiroptera: Vespertilionidae). Canadian Journal of Zoology 74:431-441.

YANG, S. H. 1996. Activity patterns and food habits of Myotis formosus and Pipistrellus abramus in Yunlin. M.S. thesis, National Taiwan University, Taipei, Republic of China (in Chinese).

Submitted 29 March 1999. Accepted 4 January 2000.

Associate Editor was Robert K. Rose. 